\title{
Una noche con Venus, una vida con Mercurio
}

\section{A night with Venus, a life with Mercury}

\author{
Verónica Andrea Malah ${ }^{1}$ y Sergio Carbia ${ }^{2}$
}

1 Médica Reumatóloga de Planta, Hospital de Clínicas José de San Martín

2 Docente Adscripto a Dermatología, Universidad de Buenos Aires

Dermatol. Argent. 2021, 27 (1): 41-42
Contacto del autor: Verónica Andrea Malah

E-mail: patomalah@hotmail.com

Fecha de trabajo recibido: 9/11/2020

Fecha de trabajo aceptado: 11/12/2020

Conflicto de interés: los autores declaran que no existe conflicto de interés.
El doctor Saldaña le debía dinero perdido en la mesa de juego, por lo que lo atendía gratis y no le cobraba los preparados que él mismo fabricaba. Aarón no recurría a él porque no le cobrara sino porque Saldaña aplicaba un nuevo método para curar el morbo francés. "Una noche con Venus, una vida con Mercurio", habia expresado el médico después de confirmar el diagnóstico. Sin embargo, la novedad de su profilaxis se centraba en el uso del arsénico - a más de los emplastos, ingesta y vapores de mercurio-, cuya sudoración despedia un ligero aroma a albaricoque.

Por fortuna, habian desaparecido las manchas que por semanas le habian inutilizado las manos y las plantas de los pies, a las que Saldaña llamaba "clavos sifiliticos". Su desaparición no implicaba la cura. "Así como desaparecieron los chancros de su miembro", le explicó, "también desaparecerán los clavos. La enfermedad, sin embargo, persistirá, siempre latente y al acecho".

(...) la enfermedad que lo aquejaba habia retornado con virulencia; los clavos sifiliticos, como llamaba el doctor Saldaña a las ronchas rosáceas, se ensañaban con su espalda y su pecho.

- Agradezca, señor Romano -interpuso el médico-, que no le hayan aparecido en el rostro. He visto narices deformadas a causa de estos clavos. -Aarón, desesperado, le exigió una medida drástica-. Aumentaré la dosis del arsénico, pero no la del mercurio. Además, recomiendo una vida célibe y reposada, comida frugal y el uso de purgantes, que yo mismo le proveeré. Las sangrías y los baños de vapor son beneficiosos.

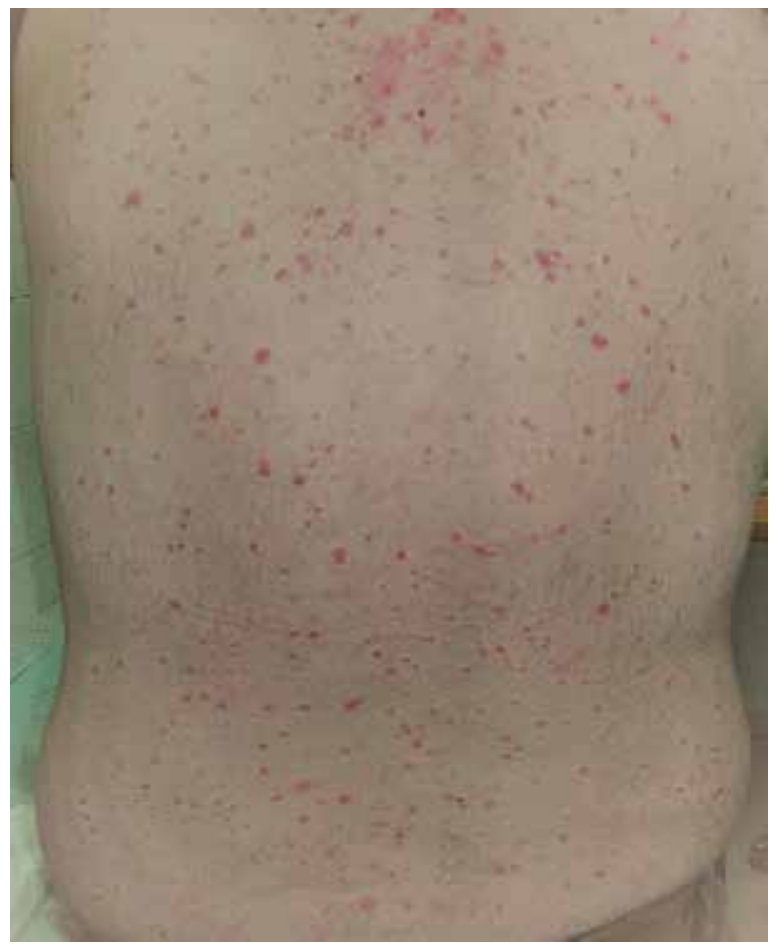

\section{FLORENCIA BONELLI (ARGENTINA, 1971)}

Nacida en Córdoba, apasionada por la literatura desde nińa, rechazó la idea de estudiar Filosofía y Letras, ya que no le atraía la docencia, decidiéndose por Ciencias Económicas.

En 1997, alentada por su esposo, comenzó a escribir historias de amor y abandonó su trabajo de contadora pública para dedicarse de lleno a la escritura. En 
1999, publicó su primera novela Bodas de odio (1999), a la que siguió una prolífica producción con obras como Indias blancas (2005), El cuarto arcano (2007) y las trilogías Caballo de fuego $(2011 / 2012)$ y del Perdón (2014/2015).

Me llaman Artemio Furia, publicada en 2009, se convirtió rápidamente en un éxito de venta y la editorial debió realizar una segunda edición solo diez días después de su lanzamiento. Ambientada en la época de la Revolución de Mayo, narra la historia de Artemio, un gaucho temido y respetado por todas las clases sociales que, convocado por la facción patriótica a luchar por la libertad, tiene un trágico y apasionado amor con Rafaela Palafox y Binda, una joven dama de ciudad.

Durante una entrevista, la escritora afirmó: "Artemio es uno de mis personajes más distintos, comenzando porque es rubio y tiene ojos celestes, pero este protagonista es un humilde homenaje al Payo Osorio, personaje de una saga de la escritora Cristina Bajo". Su decisión de bautizarlo Sebastián, si bien todos lo conocen con el apodo de Artemio, se basó en el pedido de una lectora, Analía Eder, cuyo hermano había falle- cido en un accidente hacía unos años. "Un día Analía me mandó un mail haciéndome este pedido y, cuando nos encontramos para que me cuente un poco sobre él, me sorprendí al ver que era igual a mi Artemio. Fue mágico, así que decidí cambiarle el nombre original y hacerle un homenaje a Sebastián Eder".

Catalogada por algunos críticos como la futura Corín Tellado, Bonelli reflexiona: "Me encanta, porque si llego a lograr lo que ella hizo con su trabajo (ser la segunda escritora más leída en lengua castellana después de Cervantes), es todo un placer". Dotada de una capacidad narrativa asombrosa y del deseo de contar historias intensas y sensuales, muchas de ellas enmarcadas en acontecimientos históricos del siglo XIX argentino, Florencia Bonelli se ha convertido no solo en la referente actual de la novela histórico-romántica de la Argentina, sino en una de las autoras más reconocidas de la novela popular del presente siglo.

\section{BIBLIOGRAFÍA}

Bonelli F. Me llaman Artemio Furia. 1. ${ }^{a}$ ed., Suma de letras, Buenos Aires, 2011, pp. 222,375.

\section{PERLAS}

\section{Federico Pastore}

Médico Dermatólogo y Legista. Médico de Planta de Dermatología, Hospital Dr. Enrique Tornú. Jefe del Servicio de Dermatología, Instituto César Milstein

\section{ASOCIACIÓN ENTRE LA ROSÁCEA Y LA ENFERMEDAD CARDIOMETABÓLICA}

La rosácea es un trastorno inflamatorio cutáneo crónico que se manifiesta principalmente con un eritema centrofacial acompañado de episodios de exacerbación desencadenados por diferentes circunstancias.

Se asocia a diferentes patologías sistémicas. La relación entre la rosácea y la enfermedad cardiometabólica todavía es controvertida.

La fisiopatogenia de este trastorno no está bien dilucidada. Sin embargo, la desregulación inmune y neurovascular, factores genéticos, microorganismos, factores ambientales, dieta, consumo de alcohol, tabaquismo y estrés, entre otros, están implicados en el desarrollo y la evolución de la enfermedad.

Respecto de los factores de riesgo cardiovascular evaluados:

- Diabetes: la relación entre la rosácea y la prevalencia de diabetes no alcanzó significación estadística, pero se observaron valores de glucemia en ayunas más elevados en estos pacientes.
- Hipertensión: los pacientes con rosácea tenían un aumento estadísticamente significativo tanto de la presión sistólica como de la diastólica.

- Dislipidemia: la rosácea se asoció a dislipidemia. Los valores de colesterol total, de colesterol LDL y de triglicéridos fueron estadísticamente más altos.

La rosácea mostró una correlación positiva con la hipertensión y la dislipidemia. No se pudo comprobar una asociación entre la rosácea y la enfermedad isquémica coronaria, el accidente cerebrovascular y la diabetes.

Esta información debe valorarse a fin de pesquisar las comorbilidades en este grupo de pacientes, que son vistos por dermatólogos y que requieren una evaluación clínica.

Chen Q, Shi X, Tang Y, Wang B, et ál. Association between rosacea and cardiometabolic disease: A systematic review and meta-analysis. J Am Acad Dermatol 2020;83:1331-1340.
NUEVAS OPCIONES TERAPÉUTICAS PARA EL TRATAMIENTO DE LA ROSÁCEA PÁPULO-PUSTULOSA

La rosácea es una dermatosis inflamatoria frecuente. En un porcentaje elevado de pacientes la respuesta al tratamiento es parcial, por lo que representa un desafío para el dermatólogo. Los mecanismos fisiopatogénicos involucrados son variados y no del todo conocidos. Entre las opciones terapéuticas, los antibióticos de la familia de las tetraciclinas son un instrumento eficaz por su efecto antiinflamatorio.

Este estudio comparó la eficacia y la seguridad de dos concentraciones de minociclina tópica en gel al $1 \%$ y al $3 \%$ controlado con vehículo.

Los resultados del estudio mostraron que la tasa de respuesta al vehículo fue bastante elevada, como ocurre en el caso de las patologías con evolución fluctuante. El grupo al que se le asignó la minociclina al 3\% mostró una mejoría proporcionalmente significativa después de 12 semanas de tratamiento, así como una mínima absorción sistémica.

Hampton PJ. Expanding treatment options for rosacea. Br J Dermatol 2020;183:412-413. 